\title{
Bicuspid aortic valve phenotype and aortic disease: a magnetic resonance study
}

\author{
David W Fitz ${ }^{*}$, James C Carr, Edwin Wu \\ From 2011 SCMR/Euro CMR Joint Scientific Sessions \\ Nice, France. 3-6 February 2011
}

\section{Objective}

The aim of this study was to uncover any association between bicuspid aortic valve (BAV) phenotype and aortic valve disease or aortic dilation.

\section{Background}

BAV is the most common congenital heart defect in the general population, particularly in patients requiring valve surgery. Recent studies have shown cardiovascular magnetic resonance (CMR) to be an accurate and sensitive modality for classifying BAV phenotypes.

\section{Methods}

Patients were selected retrospectively from the database at $\mathrm{NMH}$ according to IRB-approved protocols. We identified and selected 217 patients who had a diagnosis of BAV and underwent CMR angiography between 2007 and 2010. For each subject, age, gender, functional state of the BAV, pattern of fusion, aortic root diameter, mid ascending aortic diameter, proximal and distal aortic arch diameter, and primary indication at the time of the MRA were extracted from reports.

\section{Results}

We identified four valve morphologies: type 1 , fusion of the right and left cusps $(n=152)$; type 2 , fusion of the right and non-coronary cusps $(n=48)$; type 3 , fusion of the left and non-coronary cusps $(n=9)$; and unicuspid, two fusions $(n=8)$. We further characterized each type by the number of sinuses, two or three, and the presence or absence of a raphe. Comparing the three types, two sinuses were associated with a significantly higher $(\mathrm{P}<0.001)$ proportion among type 2 and type $3 \mathrm{BAV}$. Type 2 BAV was associated with moderate to severe stenosis $(\mathrm{P}=0.049)$ and a larger diameter of the mid

Northwestern University Feinberg School of Medicine, Chicago, IL, USA

ascending aorta $(\mathrm{P}=0.029)$. There was no significant difference between aortic regurgitation and aortic root diameter. Tables 1 and 2.

\section{Conclusion}

CMR is a capable imaging tool for characterizing BAV phenotype. Type $1 \mathrm{BAV}$ is the most frequent phenotype. Two sinus valves are more common among type 2 and

Table 1 Pattern of bicuspid aortic valve phenotype

\begin{tabular}{lllll}
\hline & $\begin{array}{l}\text { Type 1 } \\
(\mathbf{n = 1 5 2 )}\end{array}$ & $\begin{array}{l}\text { Type 2 } \\
(\mathbf{n = 4 8})\end{array}$ & $\begin{array}{l}\text { Type 3 } \\
(\mathbf{n = 9 )}\end{array}$ & $\begin{array}{l}\text { Unicuspid } \\
(\mathbf{n}=\mathbf{8})\end{array}$ \\
\hline $\begin{array}{l}3 \text { sinuses } \\
\text { W/ raphe }\end{array}$ & $119(78.3 \%)$ & $21(43.8 \%)$ & $2(22.2 \%)$ & $8(100 \%)$ \\
$\begin{array}{l}3 \text { sinuses } \\
\text { W/ fusion }\end{array}$ & $8(5.3 \%)$ & $6(12.5 \%)$ & 0 & 0 \\
2 sinuses & $25(16.4 \%)$ & $21(43.8 \%)$ & $7(77.8 \%)$ & 0 \\
\hline
\end{tabular}

Table 2 Clinical characteristics of single-study BAV patients

\begin{tabular}{|c|c|c|c|}
\hline & Type $1(n=108)$ & Type $2(n=33)$ & Type $3(n=8)$ \\
\hline \multicolumn{4}{|l|}{ Aortic Stenosis } \\
\hline None & 75 (69.4\%) & 14 (42.4\%) & 7 (87.5\%) \\
\hline Mild - mod & 7 (6.5\%) & $6(18.2 \%)$ & $1(12.5 \%)$ \\
\hline Moderate & $8(7.4 \%)$ & $4(12.1 \%)$ & 0 \\
\hline Mod - severe & 18 (16.7\%) & 9 (27.2\%) & 0 \\
\hline
\end{tabular}

Aortic Regurgitation

\begin{tabular}{llll} 
None/trace & $36(30.6 \%)$ & $13(39.3 \%)$ & $5(62.5 \%)$ \\
Mild - mod & $48(44.4 \%)$ & $12(36.4 \%)$ & $2(25.0 \%)$ \\
Moderate & $15(13.9 \%)$ & $7(21.1 \%)$ & 0 \\
Mod - severe & $9(8.3 \%)$ & $1(2.9 \%)$ & $1(12.5 \%)$ \\
\hline Aortic Dilation $(\mathrm{cm})$ & & \\
Root & $3.99 \pm 0.58(2.7-5.7)$ & $4.10 \pm 0.67(2.9-5.7)$ & $4.04 \pm 0.70(3.0-5.2)$ \\
MAA & $3.91 \pm 0.60(2.0-5.4)$ & $4.08 \pm 0.78(2.8-5.8)$ & $3.37 \pm 0.58(2.6-4.1)$ \\
\hline
\end{tabular}


type 3 phenotypes. Type 2 is associated with moderate to severe aortic stenosis and a larger mid-ascending aortic diameter.

Published: 2 February 2011

doi:10.1186/1532-429X-13-S1-P208

Cite this article as: Fitz et al: Bicuspid aortic valve phenotype and aortic disease: a magnetic resonance study. Journal of Cardiovascular Magnetic Resonance 2011 13(Suppl 1):P208.

Submit your next manuscript to BioMed Central and take full advantage of:

- Convenient online submission

- Thorough peer review

- No space constraints or color figure charges

- Immediate publication on acceptance

- Inclusion in PubMed, CAS, Scopus and Google Scholar

- Research which is freely available for redistribution

Submit your manuscript at www.biomedcentral.com/submit
C Biomed Central 